\title{
Quality of higher education and the labor market in developing countries: Evidence from an education reform in Senegal*
}

\author{
Dorothée Boccanfuso \\ Université de Sherbrooke \\ Alexandre Larouche \\ Del Degan, Massé \\ Mircea Trandafir \\ University of Southern Denmark and IZA
}

This version: December 2014

\begin{abstract}
While many studies examine the effect of primary education quality on labor market outcomes in developing countries, little is known about the effects at higher levels. We exploit the quasi-experiment provided by a large-scale education reform launched in Senegal in 2000 to investigate how quality improvements at the university level affect employment. Our difference-in-difference estimates suggest that young highskilled workers experienced a nine percentage-point employment gain relative to older workers. They are also more likely to have "better" jobs (in the service industry or government), suggesting a reduction in the mismatch between the quality of high-skill labor demanded and supplied.
\end{abstract}

Keywords: Higher education, employment, impact analysis, quality mismatch.

JEL Classification: I21, O15, O55.

*Boccanfuso: Department of economics and GRÉDI, Université de Sherbrooke, 2500 boul. de l'Université, Sherbrooke, Québec J1K 2R1, Canada, email: dorothee.boccanfuso@usherbrooke.ca; Larouche: Del Degan, Massé, 825, rue Raoul-Jobin, Québec, Québec G1N 1S6, Canada, email: alexandre.larouche@groupeddm.com; Trandafir: Department of Business and Economics, University of Southern Denmark, Campusvej 55, 5230 Odense M, Denmark, email: mircea.trandafir@sam.sdu.dk. We are grateful for comments provided by Sonia Laszlo and participants at the 2011 meetings of the Société Canadienne de Science Économique and Ecomod, as well as seminar participants at Concordia University and Université d'Auvergne-CERDI. We also thank CRES (Dakar, Sénégal) and Abdoulaye Diagne for providing us with the data. All remaining errors are ours. 


\section{Introduction}

Education is widely considered a key issue in the economic and social development of a country (e.g., Barro and Lee, 1994, 2013). Given the high rates of illiteracy in developing countries, most policies focus on improving access to education and most evaluation studies of the education sector in developing countries focus on access, particularly to primary education (e.g., Duflo, 2001, 2004). However, school quality is slowly emerging as an important issue in developing countries. Recent evidence suggests that quality of education is strongly associated with income and economic growth (see, for example Mingat, 1998; Bloom et al., 2006; Hanushek and Woessmann, 2008; Schoellman, 2012; Hanushek, 2013; Kaarsen, 2014; Manuelli and Seshadri, 2014), as well as with higher individual returns to education (e.g., Behrman and Birdsall, 1983; Moll, 1992; Bedi and Edwards, 2002; Zhong, 2011). Moreover, there seems to be a direct link between school quality and attainment. For instance, Hanushek et al. (2008) find that Egyptian children were more likely to drop out of primary schools of lower quality, while Harbison and Hanushek (1992) find that improved school quality reduces the repetition rate among Brazilian primary school students. Finally, Behrman et al. (2008) find that the return from investing in quantity (access) might be smaller than the return from investing in quality with respect to schooling in rural Pakistan.

Not surprisingly, the research on quality of education in developing countries focuses exclusively on primary and secondary schools, and on the effects on achievement and labor market outcomes (e.g., Harbison and Hanushek, 1992; Glewwe, 1999; Bacolod and Tobias, 2006; Handa and Simler, 2006; Behrman et al., 2008; Hanushek et al., 2008; Hanushek, 2009). Economic development, however, seems to depend not only on the average level but also on the distribution of human capital or cognitive skills, particularly at the upper tail (Castelló and Doménech, 2002; Hanushek and Woessmann, 2008). Individual returns to education are also highest at the tertiary education level (Barro and Lee, 2013). Still, higher education and its quality are largely overlooked when it comes to developing countries, both in economic research and in policy design (Kimenyi, 2011). 
The purpose of this paper is to estimate the effects of improvements in the quality of higher education on the labor market outcomes of highly-educated individuals. In particular, we focus on the short-term effects of an education reform in Senegal in the early 2000s, the Development Program for Education and Training (Programme de développement de l'éducation et de la formation, PDEF). We study the short-term effects of this reform because its objective in the short-run was an increase in the quality but not in the quantity of education at the university level. Because of data limitations, we can only analyze effects on employment and not on other labor market outcomes such as wages or job quality. This is still an interesting outcome since previous studies found that, unlike in developed countries, a higher-level degree in a developing country does not necessarily lead to better employment prospects (e.g., Pritchett, 2001; Guarcello et al., 2008; Pauw et al., 2008; Hanushek et al., 2011). In particular, unemployment is often highest among young university graduates in sub-Saharan Africa (Calvès and Schoumaker, 2004; Guarcello et al., 2008; Fan and Stark, 2007). If the higher unemployment rate of highly-educated workers is due to a mismatch between the quality of labor demanded and supplied in the high-skilled labor market (Pauw et al., 2008; Ordine and Rose, 2011), then improvements in the quality of higher education can lead to higher employment rates. ${ }^{1}$

Senegal is an appropriate setting for this exercise because its labor market exhibits this pattern of high unemployment rates for highly-educated individuals. Table 1 shows the relationship in 2002 between the unemployment rate and education for individuals living in Dakar, Senegal's largest city. Although household heads with university training have the lowest unemployment rate, the situation is exactly the opposite for dependents. In the short term, the individuals most likely to benefit from the reform are the highly-educated young, who (as we show later) are also almost exclusively dependents, suggesting that unemployment is a severe problem among those most likely affected by the reform.

We use data from two surveys of the Senegalese population, one conducted right before

\footnotetext{
${ }^{1}$ In the rest of the paper we use the terms "high-skilled," "highly-educated" and "university-trained" to refer to individuals who obtained at least some education at the university level.
} 
the implementation of the reform (in 2001) and one five years later (in 2006), to estimate a difference-in-difference model. Because we cannot precisely identify in our data the individuals who benefit from the reform, we restrict our sample to individuals 20-39 years old and we use age to proxy for exposure to the reform. This leads to a trade-off between the size of the treated group and the contamination of both the treated and the control group: a wider age interval includes in the treated group a larger fraction of the individuals educated (at least partially) after the start of the reform, but also a larger number of individuals who completed their education before the first year of the reform. Taking this contamination into account, our results are generally robust to the definition of treatment. Our preferred definition is the 20-26 year-olds, a group that seems to offer the most balanced combination of size and contamination.

Our estimates suggest that the reform had strong positive short-term effects on the employment rate of all groups of young highly-educated workers. For our preferred definition of reform exposure, 20-26 year-olds, we find an increase of about nine percentage points in their employment rate as compared to older highly-educated workers. This represents a 16 percent increase from their employment rate in 2000. In order to gauge the magnitude of our results, we compare them to existing estimates of returns to college quality. There is a vast literature on the returns to quality of higher education in developed countries such as the United States (see Zhang, 2005, for a review). Almost all of this literature deals with effects on earnings due to the high level of employment among college graduates. ${ }^{2}$ The literature on the returns to quality of education in less developed countries is usually concerned with pre-university education (e.g., Harbison and Hanushek, 1992; Hanushek et al., 2008; Behrman et al., 2008; Malamud and Pop-Eleches, 2010). The closest study to ours is Saavedra (2009), who uses a regression discontinuity design to estimate that attending a better-quality university in Colombia increases employment post-graduation by 16 percent. This estimate represents an

\footnotetext{
${ }^{2}$ One exception is Böckerman et al. (2009), who estimate that the employment rate of graduates of polytechnics (a non-university type of higher education) in Finland are 13.6 percentage points higher in the first year after graduation than the corresponding employment rate of graduates of vocational colleges.
} 
intention-to-treat effect comparable in magnitude to our estimates.

We verify the robustness of our results to several specification checks. One particular issue is that this improvement in the labor market outcomes of young workers could be due to a skill-biased economic expansion over the study period. If this was the case, we would expect to find a negative relationship between age and the employment rate of high-skilled workers, and an increase in the labor force participation and in the dropout rate (entry into the labor market) of young high-skilled workers. However, we find no evidence of a decline in the employment rate of 37-49 year-old high-skilled workers as compared to younger workers. We also find evidence of a reduction in the labor force participation of young high-skilled workers, as well as an increase in university enrollment. We conduct several additional checks, such as a triple-difference model that adds 20-39 year-old high school-educated individuals as an additional control group. The estimates from this model confirm that our estimates are not driven by age effects. We also estimate a placebo specification among individuals with only high school education, which produces small and insignificant results indicating that our baseline findings are not due to general shifts in labor demand. Taken together, these results suggest that there is indeed an increase in the employment rate of young highly-educated workers after the education reform that is not due to a skill-biased economic expansion.

Several studies of the labor market in developing countries (e.g., Calvès and Schoumaker, 2004; Guarcello et al., 2008; Fan and Stark, 2007) posit that the high rate of unemployment among young highly-trained individuals is due to a "waiting queue" for jobs in the formal sector. According to this scenario, a rise in the employment rate of high-skilled workers is due to an expansion of the formal sector. However, our robustness tests do not suggest that this is the case. In addition, in the last part of the paper we investigate the sources of the employment growth found. Because of data limitations, we can only examine the choice of industry and of employer by young high-skilled workers. We find an increase in the fraction of individuals employed in services to the detriment of manufacturing (and of other industries), as well as a large decrease in self-employment accompanied by an increase 
in government jobs. These suggest that high-skilled individuals are better able to find jobs that pay better than the outside option (self-employment) after the reform, and that they mostly work in the service sector and for the government. These results provide suggestive evidence in favor of our hypothesis that the mechanism explaining the observed employment growth is the reduction in the quality gap between labor supplied and demanded due to the reform.

Our study has several limitations. First, we only examine the short-term effects of the reform. However, proof of immediate results is essential for the continued implementation of a reform in volatile political environments such as in much of the developing world. Second, we cannot determine the effect of the reform on the quality of employment or on wages because of data limitations. We do not believe that this is a major concern since none of our robustness tests suggests the presence of some factor that pushes younger high-skilled workers to accept lower quality jobs after the reform. Moreover, we interpret the reduction in self-employment and the rise in government jobs as suggestive evidence that individuals are able to find better paying and presumably better quality jobs after implementation of the reform. Third, we cannot distinguish between full or partial exposure to the reform. However, this implies that our estimates are likely a lower bound for the true effects of the reform. Fourth, data limitations prevent us from identifying the mechanism through which the reform leads to improved labor market prospects. Finally, similar to many other studies using data from Sub-Saharan Africa, we have a relatively small sample, mostly due to the size of the high-skilled workforce in the Senegalese economy. While this is likely to generate imprecision in our estimates, the effects are robust to several specification checks and generally statistically significant.

The rest of the paper proceeds as follows. The next section presents the institutional background and the educational reform in Senegal. The empirical strategy is described in section 3 and the data used in section 4 . The results from the baseline specification and from the various robustness tests, as well as the choice of industry and employer are discussed in 
section 5. Section 6 concludes.

\section{Institutional background}

The higher education system in Senegal is based on the French model. ${ }^{3}$ For the period under study, this means that university coursework generally starts at around age 19 for a regular trajectory through the education system. Most subjects require four years of study for a successful completion, but degrees are awarded along the way and students can quit their studies after obtaining one of these diplomas. The first degree comes after the first two years and represents general university training (diplôme d'études universitaires générales, $D E U G$ ), followed by another degree after a third year of more specialized studies (licence) and the final degree after a fourth year of specialized studies (maîtrise). During the late 1990s, a majority of students quit their studies after obtaining a $D E U G$, the first and most basic of these degrees, and seemed to have some difficulties in the labor market due to differences between the knowledge acquired and that desired by employers (Samb et al., 1999).

Against this backdrop, Senegal included some specific goals for higher education in the major reform of its education system undertaken in 2000 as part of the Millennium Development Goals. The Development Program for Education and Training (Programme de développement de l'éducation et de la formation, PDEF) had as main objectives to increase access to basic education, to improve the quality of learning and to make system management more efficient, affecting all education levels over a period of ten years from 2000 to 2010 (Ministère de l'éducation, 2003). ${ }^{4}$ Although the emphasis was on primary and to some extent secondary education, the reform included actions and objectives targeted specifically to the higher education. Moreover, higher education expenditures did not fall during the

\footnotetext{
${ }^{3}$ The alignment of Senegalese higher education to the LMD (Licence-Master-Doctorat) international system was planned in 2002. However, this change was implemented only starting from 2008, after our study period.

${ }^{4}$ The initial name was of the program was the Ten-Year Program for Education and Training (Programme décennal de l'éducation et de la formation), with the same acronym.
} 
first half of the program. Panel A of Table 2 shows that the share of higher education in total expenditures on education was constantly above the planned levels and that it did not fall below 23 percent throughout the entire period. Given that public spending on education increased during the same period as shown in panel B of Table 2, this implies that spending on higher education actually increased at a steady pace between 2000 and $2005 .^{5}$

The two main objectives of the reform with respect to higher education concerned improved access and better quality of instruction. The first objective involves the construction of regional university centers to reduce the pressure on the country's two main universities, Cheikh Anta Diop in Dakar and Gaston Berger in Saint Louis (Ministère de l'éducation, 2003). However, the first of these new institutions of higher education opened in 2007 (Direction de la planification et de la réforme de l'éducation, 2009), making this aspect of the reform not relevant for our study as we restrict our attention to the effects of the reform over the period 2001-2005, as we detail in section 4 .

The second goal of the reform and the one we focus on in this paper was to improve quality. This objective was deemed "imperative" and several quality indicators were identified and targeted, such as the dropout rate, the distribution of students across technical and non-technical fields, and the match between university training and employment (Ministère de l'éducation, 2003). During the first phase covering the years 2001-2003, the budget allocated to quality improvements represented $42 \%$ of operating expenditure and $50 \%$ of new investment at the tertiary level (Ministère de l'économie et des finances du Sénégal, 2001). The actions undertaken involved improvements in the technology used in instruction and in laboratories, enhancements to libraries and information systems, the allocation of additional research funds, and a realignment of fields of specialization to follow closer the demands of the labor market (Ministère de l'éducation, 2003).

The implementation of the reform favored the higher education sector, which received

\footnotetext{
${ }^{5}$ The cost per student is also much higher in higher education. For example, the unit cost associated with a student at the university level can be 5-20 times higher than that of a secondary and primary student (Direction de la planification et de la réforme de l'éducation, 2008).
} 
more resources than planned, to the detriment of primary and secondary education. ${ }^{6}$ Most of the expenses were allocated to two areas. First, the scholarship program was extended to nearly all students enrolled in higher education, such that expenses on scholarships rose by a factor of 5.6 by 2010. Second, several investments were made in student residences and cafeterias that improved the living conditions of students. These strategies likely had the effect of retaining better quality students who would have dropped out early due to higher labor market returns as compared to the cost of continuing their education. In addition, university budgets were unblocked and the salaries of educational staff were raised in an effort to attract better quality instructors.

One major development in the implementation of the reform was the introduction of the new "Carte universitaire" in 2012. This policy touched upon several areas. First, it emphasized the decentralization and autonomy of institutions of higher education, as well as the need to involve local authorities and communities in the management of these institutions. As a result, local governments provide part of the funding of universities. Second, there was a push for diversification in the offer of education programs, including professional programs, with the explicit objective of aligning the instruction to the needs of the labor market (one such example is the restructuring of the École Supérieure Polytechnique de Thiés). Finally, these changes were accompanied by measures aimed at harmonizing and assuring the coherence and coordination of teaching and research across universities in Senegal. In addition, there was also a push toward the inclusion of more information technology in instruction as well as for more distance learning.

Some suggestive evidence on the results of these actions is presented in Table 3. Panel A of this table shows the actual enrollment in 2000 and in 2007 at Université Cheikh Anta Diop in Dakar, the main university in Senegal, as well as the predicted enrollment for the period 2000-2007 based on the SIMULPDEF prediction model developed by the Centre de Recherches Economiques Appliquées for the Ministry of education (Diagne, 2012). Panel

\footnotetext{
${ }^{6}$ The presentation of reform policies is based on the discussion in Diagne (2012).
} 
B lists the projected required faculty size at the same university. Based on the 2000 levels and the objectives of the reform, the Ministry of education projected a general decline in enrollment, particularly in humanities, accompanied by a rise in the number of faculty. In reality, enrollment in all fields increased by 2007 by a factor of at least $2 .{ }^{7}$ Since capacity constraints did not change during this time, a likely explanation for this trend is that the dropout rate fell, i.e., students pursued their education until obtaining a licence or maîtrise. ${ }^{8}$ Note that although the additional enrollment could cause lower quality of education for students obtaining the more advanced degrees due to a higher student-to-teacher ratio, it would presumably improve the quality of the overall graduating class by increasing the share of students finishing with the more advanced degrees. ${ }^{9}$

Finally, the reform can also increase the quality of high-skilled labor through positive selection. A perceived improvement in the quality of higher education and in the labor market prospects post graduation can cause some higher-ability high school graduates to pursue higher education instead of entering the labor market immediately. In addition, some of the high school graduates that seek higher training abroad can choose to obtain it in Senegal. As a result, the quality of both the student pool and of the highly-educated labor force improve and, to the extent that there are positive peer effects in learning, the quality of higher education improves even further.

\footnotetext{
${ }^{7}$ The numbers in Tables 2 and 3 suggest that expenditures per student declined during the study period, which could be interpreted as a decline in the quality of education. This may not necessarily be the case if the large initial value is due to large investments in fixed assets or if resources were underused initially. This explanation is supported by the fact that the student-teacher ratio was expected to fall over the same period, as indicated by the numbers in Table 3 .

${ }^{8}$ Other potential explanations are an increased demand for education following the announcement of the reform and its objective or general trends in the demand for higher education. However, these explanations would hold only if higher education was underutilized before the reform. This hypothesis is unlikely to be true, based on the fact that part of the reform was to add capacity to the higher education system. In any case, a higher labor supply lowers the employment prospects of young university-trained individuals and reduces the effects of the reform in the labor market, an aspect to which we return in section 5.2.

${ }^{9}$ In other words, the quality of the marginal university-trained individual is lower after the reform, but the quality of the average university-trained individual is higher.
} 


\section{Empirical strategy}

The empirical strategy exploits the fact that the education reform is an event presumably exogenous to the labor market experience of any particular individual. As such, we use a difference-in-difference approach where treatment status is given by exposure to university training after the implementation of the PDEF. As in any difference-in-difference model, the estimation is based on a pre-post comparison of mean outcomes between treated individuals (i.e., those who obtained at least part of their education after the implementation of the reform) and control individuals. Since the reform was not targeted at a particular demographic group, controlling for observed socio-economic characteristics of the individuals should not change the estimates, but it can improve the explanatory power and the precision of the estimation. We start by restricting the sample to university-trained individuals because individuals who obtained higher education before the reform are likely to be the best comparison group for those who obtained their higher education after the reform. The difference-in-difference model estimated in this sample has the following form:

$$
P\left(Y_{i t}=1 \mid T_{i}, P_{t}, X_{i t}\right)=\Phi\left(\beta_{0}+\beta_{1} T_{i}+\beta_{2} P_{t}+\beta_{12} T_{i} P_{t}+\delta X_{i t}\right),
$$

where $Y_{i t}$ is a binary measure of labor market performance, $T_{i}$ is a dummy variable indicating whether at least part of the education of individual $i$ was obtained after the reform, $P_{t}$ is an dummy variable for period $t$ being after the implementation of the PDEF, $X_{i t}$ is a vector of socio-economic characteristics, and $\Phi(\cdot)$ is the standard normal distribution function. We estimate the model by probit and we correct the standard errors for correlations within regions (e.g., due to local labor market conditions) by clustering them the region level. ${ }^{10}$

The causal effect of interest is the effect of the education reform on university-trained individuals, which is an average treatment effect on the treated. To the extent that the control group provides an appropriate counterfactual for the average outcome of the treated

\footnotetext{
${ }^{10}$ Senegal is divided into ten regions: Dakar, Ziguinchor, Diourbel, St-Louis, Tamba, Kaolack, Thiès, Louga, Fatick and Kolda.
} 
group in the absence of the reform, Puhani (2012) shows that the treatment effect can be calculated as:

$$
\begin{aligned}
\widehat{A T T}=\left(E\left[Y \mid T_{i}=1, P_{t}=1\right]-E\left[Y \mid T_{i}=1, P_{t}=0\right]\right) \\
\quad-\left(E\left[Y \mid T_{i}=0, P_{t}=1\right]-E\left[Y \mid T_{i}=0, P_{t}=0\right]\right) \\
=E\left[\Phi\left(\beta_{0}+\beta_{1}+\beta_{2}+\beta_{12}+\delta X_{i t}\right)\right]-E\left[\Phi\left(\beta_{0}+\beta_{1}+\beta_{2}+\delta X_{i t}\right)\right]
\end{aligned}
$$

As we detail in the next section, we cannot precisely identify individuals who obtained their higher education after the PDEF. Instead, we proxy for exposure to the reform with age and define the treatment group as the set of university-trained individuals in a certain age group. This means that we effectively estimate an intention-to-treat effect. It also creates two potential problems. First, it is possible that the differential evolution of the outcome of interest between the treated and control groups is due to "age effects," time-varying unobservable characteristics that are correlated with both the employment probability and the age of individuals. To the extent that these age differences are similar across different groups in the population, we can use high school trained individuals to eliminate them. Specifically, we estimate difference-in-difference-in-difference (triple-difference) models in which we include individuals with high-school education in the same age groups as an additional control group. The triple-difference model is:

$$
\begin{aligned}
P\left(Y_{i t}=1 \mid T_{i}, P_{t}, X_{i t}\right)=\Phi\left(\beta_{0}\right. & +\beta_{1} T_{i}+\beta_{2} P_{t}+\beta_{3} U_{i}+\beta_{12} T_{i} P_{t} \\
& \left.+\beta_{13} T_{i} U_{i}+\beta_{23} U_{i} P_{t}+\beta_{123} T_{i} P_{t} U_{i}+\delta X_{i t}\right)
\end{aligned}
$$

where $U_{i}$ is an indicator for individual $i$ being university-trained and the effect of the reform is determined by the triple interaction coefficient $\beta_{123}$. As before, the standard errors are clustered at the region level to control for correlations within regions.

The second potential problem is related to the imperfect identification of individuals exposed to the reform. Since it is unlikely that all individuals in an age group obtained 
their education after the reform or that all remaining individuals obtained their education before the reform, this leads to a potential contamination of the treated group, of the control group, or both. ${ }^{11}$ Formally, suppose that exposure to the reform is imperfectly observed, with $T_{i}^{*}$ an indicator of unobserved actual exposure, and suppose that a fraction $\delta_{T}$ of the treatment group did not obtain their education after the PDEF $\left(T_{i}^{*}=0\right.$ in the post-reform period), while a fraction $\delta_{C}$ of the control group did $\left(T_{i}^{*}=1\right.$ in the post-PDEF period). For simplicity, suppose also that the effect of PDEF on the outcome studied is constant across all individuals, $\Delta$, and that there is no trend in the outcome among the unaffected individuals:

$$
\begin{aligned}
& E\left[Y \mid T_{i}^{*}=1, P_{t}=1\right]-E\left[Y \mid T_{i}^{*}=1, P_{t}=0\right]=\Delta, \\
& E\left[Y \mid T_{i}^{*}=0, P_{t}=1\right]-E\left[Y \mid T_{i}^{*}=0, P_{t}=0\right]=0 .
\end{aligned}
$$

In this case, the estimated effect of the reform is:

$$
\begin{aligned}
\widehat{A T T}= & \left(1-\delta_{T}\right)\left(E\left[Y \mid T_{i}^{*}=1, P_{t}=1\right]-E\left[Y \mid T_{i}^{*}=1, P_{t}=0\right]\right) \\
& -\delta_{C}\left(E\left[Y \mid T_{i}^{*}=1, P_{t}=1\right]-E\left[Y \mid T_{i}=1, P_{t}=0\right]\right) \\
= & {\left[1-\left(\delta_{T}+\delta_{C}\right)\right] \Delta, }
\end{aligned}
$$

which underestimates in absolute value the true effect, and the size of the bias depends on the cumulative fraction of contamination in the treated and in the control group.

\section{Data}

The data comes from two household surveys, the Deuxième enquête sénégalaise auprès des ménages (ESAM-II), conducted in 2000-2001, and the Enquête de suivi de la pauvreté au Sénégal (ESPS), conducted in 2006. These surveys are rather similar as they had the same

\footnotetext{
${ }^{11}$ Hotz et al. $(1997,2005)$ present a thorough analysis of contamination of the control group in a different setting.
} 
main objective of determining the poverty profile in Senegal and they both used questionnaires based on extensions of the Core Welfare Indicators Questionnaire. ${ }^{12}$

The persons included in the ESAM-II survey were interviewed twice: once in June-August 2000 and once in February-April 2001. Individuals not in school who already obtained university training by the time of the survey must have done it before the implementation of the PDEF, which came into effect during the 2000-2001 academic year. Thus, this survey provides a snapshot of the situation right before the implementation of the education reform. The second survey, ESPS, was conducted in one wave between December 2005 and April 2006 so some of the individuals included acquired part or all of their university training after the implementation of the reform (partial or full exposure to the reform). In addition, since the survey was conducted before any of the additional higher education institutions opened, the only aspect of the reform in effect during this period is the quality improvement. To reduce the effects of seasonality in the labor market when comparing the two surveys, we only use the responses in the second wave of ESAM-II, which was conducted at almost the same time of the year as the ESPS. To obtain nationally-representative figures, we combine the sample weights used in the two surveys based on the assumption that the structure of the population did not change significantly in the period between the two surveys and provide weighted statistics and regression results throughout the paper.

Several data limitations dictate our choice of variables. First, both surveys include information on the labor force participation and employment status of surveyed individuals but not on their wages or occupation, which limits our choice of outcome variables. Our main dependent variable is employment status, but we also study the labor force participation decision, school enrollment, the industry of employment and the type of employer. Second, the ESAM-II survey does not distinguish between the different higher-education degrees (DEUG, licence or maîtrise). To ensure comparability across surveys, we define high-skilled

\footnotetext{
${ }^{12}$ The response rates of the two surveys were 99.9 percent for ESAM-II and 99.7 percent for ESPS (Archivage National des Données du Sénégal, 2012a,b). Therefore, our results are not affected by nonrandom response.
} 
individuals as persons who finished at least one year of university studies. ${ }^{13}$ Finally, in most specifications we include a set of socio-economic variables that influence labor market participation and job-search intensity, such as age, gender, marital status and the relationship to the household head, as well as variables describing the local labor market, such as the region of residence and the degree of urbanization of the place of residence. ${ }^{14}$

We restrict the sample to highly-educated individuals in the 20-39 age group. The minimum age in the sample, 20 years, represents the age after one year of university coursework when following a regular path in the education system. By setting the maximum age to 39 years, we keep only recent graduates and young workers for a more comparable sample. Finally, in the baseline specification we restrict the sample to individuals in the labor force, working (employed and self-employed) or unemployed, and exclude persons still in school or out of the labor market for other reasons, although we relax this restriction in some specifications.

As mentioned before, we proxy for reform exposure with the aid of an age group and use the rest of the sample as the control group. We start by providing a general picture of exposure to the reform in the ESPS survey in order to determine the relevant age group. First, note that individuals under 24 must have obtained at least part of their higher education after the reform simply because of the total number of years required. For some of the older individuals, we can infer if they were exposed to the reform based on their degree (e.g., a 26 year-old who obtained a 4-year degree must have followed some university courses after the implementation of the PDEF). Finally, we use the questions on school attendance during the survey year and during the previous year included the ESPS survey.

Figure 1(a) shows the fraction of highly-educated individuals identified as exposed to the reform for at least one year, calculated as described above. ${ }^{15}$ The figure shows that

\footnotetext{
${ }^{13} \mathrm{~A}$ similar situation applies to high school educated individuals.

${ }^{14} \mathrm{In}$ particular, we include a second-degree polynomial in age and indicators for gender (women), residence (rural, urban other than Dakar, reference category: urban Dakar), region (10 regions, reference category Dakar), marrital status (mono- or polygamous marriage, reference category: single) and relationship to household head (spouse, child, or other, reference category: head of household).

${ }^{15}$ Note that this approach gives us a lower bound of the fraction of individuals affected by the reform,
} 
the only non-contaminated treatment group is the 20-24 year-olds and that the degree of contamination of the treatment group increases as age increases. Figure 1(b) shows the cumulative distribution of reform exposure by age, again based on our imperfect measure of exposure. Even with this underestimate, a relatively large fraction of exposed individuals are excluded from the treated group if treatment is defined as the 20-24 year-old bracket, suggesting an inverse relationship between the two contamination proportions $\delta_{T}$ and $\delta_{C}$. However, note that an increase in the age group used to define treatment, at least for small treated groups, leads to more overall contamination due to the relative size of the treated and control groups. For example, suppose we increase the treated group from 20-24 to 20-25 year-olds. This means that we shift 25 year-olds from the control group to the treated group. The amount of contamination in the control group does not change by much, since 25 yearolds do not represent a large part of the 25-39 year-old group (the number of highly-educated individuals in each age cell is generally increasing with age simply because people can obtain more education over time). However, the contamination of the treated group increases by more because 25 year-olds are a relatively large part of the $20-25$ year olds. ${ }^{16}$

In addition, the size of the treated group varies directly with the width of the age interval used to define exposure to the reform. Therefore, we have a trade-off between contamination of the two groups and size of the treated group. Our preferred definition of treatment is the 20-26 age group because Figure 1(a) shows that a minimum of approximately 80 percent of individuals in each age cell are exposed to the reform and Figure 1(b) indicates that about 80 percent of all individuals identified as exposed to the reform are included in this age group. ${ }^{17}$

Table 4 presents the descriptive statistics for this definition of treatment, separately for each period (survey). The table shows that most of the highly-educated individuals are male and live in the urban areas of Dakar. While there are some differences with respect

since we cannot identify all the individuals older than 24 who had at least part of their university training after the reform, but before 2005. Note also that this approximation is farther from the true fraction as age increases.

${ }^{16}$ Indeed, our crude measure of overall contamination is strictly increasing with the width of the age interval used to define exposure to the reform between 20-25 and 20-29.

${ }^{17}$ These numbers should be taken as suggestive because of the issues mentioned earlier. 
to the other demographic characteristics between the individuals in the treated and in the control group, these tend to be mostly similar in the two periods. For instance, the control group tends to have higher fractions of married individuals in both periods, as well as higher fractions of household heads. Also, employed individuals in the control group are more likely to work for the government or in the "other industry" category, but again these differences tend to persist in both periods. Both these differences and the characteristics of each of the two groups are generally similar between the two periods. This suggests that the differencein-difference strategy should eliminate these time-invariant differences and that controlling for socio-economic characteristics in the regressions should not influence our estimates, which would be expected if the control group provides a valid counterfactual for the treated group.

More importantly, the table shows a sizable (16 percentage point) increase in the employment rate of 20-26 year-old individuals compared to a relatively stable employment rate for the 27-39 year-old individuals. This is a preview of our main results, suggesting that the reform led to better employment prospects for the individuals likely to be affected.

We should note at this point the relatively small size of our sample. As it will become apparent when we include high school-educated individuals in the analysis, this is due to the small fraction of the Senegalese population that acquires higher education. This is a problem that would likely appear in a study of other developing countries as well and that could be solved only by using large data sets such as from a national census, which is unfortunately not possible in our case.

\section{Results}

\subsection{Baseline specification}

Table 5 contains the marginal effects (average partial effects) corresponding to the effect of the reform estimated from the baseline empirical strategy, both as a difference-in-difference 
(columns 1 and 2) and as a triple-difference (columns 3 and 4). ${ }^{18}$ As mentioned before, all specifications are weighted using sample weights and allow for within-region correlations in errors. ${ }^{19}$ We start in panel A with the effect of the PDEF for our preferred definition of treatment, 20-26 year old individuals. The estimate in column 1, from a simple differencein-difference specification without controls, indicates that the employment rate of 20-26 year old individuals increased after the reform by 12 percentage points as compared to the employment rate of 27-39 year old individuals. ${ }^{20}$ This represents a 21 percent increase in their employment rate as of 2000 .

In the next column, we add controls to eliminate a potential bias due to differences in demographic characteristics between the two groups and their effect on labor market outcomes. The estimated effect drops slightly to nine percentage points (still a 16 percent increase from the employment rate in 2000) and remains significant. Finally, we estimate the triple-difference specification in order to eliminate any potential age effects that could drive our estimate. As before, we estimate both a specification without controls (in column 3) and one with controls (in column 4). In both cases the estimates are very similar to the ones in the first two columns, though an increase in standard errors reduces their significance level.

A small sample size can cause problems in terms of precision but also in terms of bias due to the sampling scheme. To alleviate this concern, we bootstrap the marginal effects calculated above and provide in brackets the bias-corrected 95 percent confidence interval from 1,000 replications. Although the confidence intervals are somewhat larger and now include null effects at a 95 percent level, we cannot reject relatively large effects of the reform. In addition, the estimated bias is small, of the order of 1 percentage point in all cases. All of these make us confident that our estimates are not driven by a small sample size.

\footnotetext{
${ }^{18}$ The estimated effects from linear models (available upon request) are very similar to the marginal effects from probit regressions.

${ }^{19}$ The results from unweighted regressions (available upon request) are quantitatively and qualitatively similar.

${ }^{20}$ Similar estimates are obtained when the control group is restricted to younger individuals such as those between 27 and 34 years of age (results available upon request).
} 
In panel $\mathrm{B}$, we study the sensitivity of our estimates to different definitions of exposure to the reform. We vary our treated age group from 20-25 to 20-29 year-olds (in all cases, the rest of the 20-39 year-olds form the control group). ${ }^{21}$ As before, adding the controls to either the difference-in-difference specification or to the triple-difference specification produces little change in the estimates. Similarly, age effects do not seem to be of concern as the effects in the difference-in-difference model are similar to those in the triple-difference model. More importantly, the effects are monotonically decreasing with the size of the treated group, just as predicted by an increasing degree of overall contamination of the treated and of the control group. Using our crude measure of contamination, we can provide some back-of-the envelope calculations of the true effect. With the exception of the 20-25 year olds, all the effects corrected for contamination are between 6.9 and 12.8 percentage points. ${ }^{22}$

Our estimates are likely lower bounds of the true effect, implying that the education reform had significant employment effects among young high-skilled workers. If this effect is due to a mismatch in the quality of education demanded and supplied in the high-skilled labor market that is reduced after the implementation of the PDEF, the only increase in employment once this mismatch is completely eliminated comes from new jobs. As a result, the medium and long-term effects of the reform are presumably different from the short-term effects of the reform estimated in this paper.

\subsection{Robustness checks}

Identification in difference-in-difference models is based on two assumptions: that the control group provides an appropriate counterfactual for the treated group in the absence of the intervention, and that the only factor influencing the outcome is the intervention (exogeneity of the reform). In addition, we also need to assume that the composition of the treated and of

\footnotetext{
${ }^{21}$ We estimated all the other specifications in the paper for these additional definitions of treatment. The results, available upon request, are similar to our preferred definition of treatment (20-26 years old).

${ }^{22}$ The effects corrected for contamination are, in order from $20-25$ to $20-29$ : $0.331,0.128,0.118,0.086$, and 0.069 . The true effects in these samples are likely even closer to each other since our underestimation of overall contamination is presumably increasing with the age group used to define exposure to the reform.
} 
the control group is not affected by the reform. Any violation of these assumptions produces biased estimates. We already showed in Table 5 that our results do not seem to be driven by age effects, which suggests that older workers are indeed a good counterfactual for young workers, our treated group. In the rest of this section, we provide evidence in support of the second assumption, that our estimates capture only the effect of the reform. We focus particularly on scenarios that would bias our coefficients upward.

Senegal experienced strong economic growth during this period. Data from World Bank's World Development Indicators show that the average yearly growth rate during the postdevaluation decade (1995-2005) was 4.5\%. In addition, the country went through a period of strong and sustained growth between 2002 to 2005, mostly due to an agricultural sector boosted by favorable weather conditions (e.g., $17.3 \%$ growth rate in 2003), and to public investments including the massive development of roadways and other major infrastructure (between 3 and 6\% growth from 2002 to 2005). Although the industrial sector grew on average by $5 \%$ over this period, it is obvious that the economic growth experienced by Senegal over this period cannot be solely traced to skilled labor.

Still, if the economic growth was skill-biased in the sense of an increased demand for highskilled labor, our estimation strategy would incorrectly attribute the rise in the employment rate of young workers to the reform. We provide several pieces of suggestive evidence against this scenario. First, we investigate if slightly older high-skilled workers also experienced an increase in their employment rate. In panel $\mathrm{A}$ of Table 6, we provide the results from a placebo test based on a specification identical to our baseline difference-in-difference model but estimated in the sample of 30-49 year-old university-educated workers where treatment is defined as 30-36 year-old individuals. We find a small (1.6 percentage point) and statistically insignificant reduction in the employment rate of 30-36 year-olds as compared to older workers. This suggests that any economic expansion must have affected only young highskilled workers. If this were true, we would expect to observe an increase in the labor force participation of young high-skilled workers. Panel B of Table 6 reports estimated 
reform effect from a specification based on equation (1) using labor force participation as the dependent variable in the sample of high-skilled individuals in and out of the labor force. The estimates suggest that young high-skilled individuals actually experienced a slight decline in labor force participation. In order to eliminate age effects, we also estimated a triple-difference model. The results, reported in Panel C, show again that young high-skilled individuals did not increase their labor force participation over the sample period. Taken together, these findings provide evidence against the possibility that our results are driven by the expansion of the Senegalese economy. ${ }^{23}$

These results also provide evidence against a "substitution effect." If employers have a limited number of jobs, they might substitute younger workers for the already-employed older workers if the quality of younger workers is higher. This would cause the employment rate of younger workers to go up and that of older workers to fall, artificially increasing the estimated effect of the reform. To the extent that the quality of a potential employee is based on their academic training and on-the-job learning and experience, we would expect this type of substitution to be more prevalent for individuals of closer age to our treated groups (in other words, younger workers are probably not good substitutes for more experienced workers). We can then obtain some some suggestive evidence on the presence of substitution effects by comparing the employment rate of individuals slightly older than our treated group to that of even older individuals. The results in panel A indicate that slightly older individuals experienced no worse labor market outcomes than older and more experienced high-skilled individuals. In addition, the estimates obtained when using only individuals 27-34 years old as control (available upon request) are virtually identical to our baseline results. Both of these findings suggest that substitution effects are not driving our results.

To further investigate the possibility that our results are driven by other factors, we

\footnotetext{
${ }^{23}$ Another possibility is that almost all older workers are already employed and the expansion of the economy has to be met by increased employment of young workers. However, this is unlikely to be the case as the labor force participation rate of workers in our control group is around 74 percent in both periods. This suggests that that there is still excess labor supply in this age group, but also that the demand for these workers did not change substantially over our sample period.
} 
conduct another placebo experiment where we estimate equation (1) on the sample of 20-39 year-old high school educated individuals, using the same treatment definition as before. The short-term objectives of the PDEF with respect to high school education were almost exclusively related to access, such as the construction of new schools and new classrooms. These effects would take some time to be seen and therefore we should not see any effect of the reform in this sample. Indeed, the estimated effects shown in panel D of Table 6 are very small (2.3 percentage points) and statistically insignificant, suggesting again that our estimates are not capturing other factors such as an expansion of the economy.

Another potential concern is that the results are driven by sample selection, e.g., if the reform influences labor force participation. Our results are upward biased if young highskilled individuals are more likely to leave the labor force, thus reducing the number of individuals actively looking for a job. In this case, we would find a higher employment rate even though there is no real positive effect of the PDEF on employment. The estimates in panels $\mathrm{B}$ and $\mathrm{C}$ of Table 6 shed some light on this potential issue. In panel $\mathrm{B}$ we find a relatively larger (9.1 percentage point) decline in the labor force participation of young workers as compared to older high-skilled workers, although still statistically insignificant. However, this decline could simply be due to "age effects": we would observe a reduction in the share of labor force participants among younger workers if the general trend is for younger people to obtain more education. The estimates in Panel $\mathrm{C}$, based on a specification that eliminates age effects, point to no difference in the labor force participation of younger and older high-skilled workers (1.3 percentage points). This suggests that, indeed, the reduction in labor force participation found initially is due entirely to age effects. To further confirm this, we estimate our baseline difference-in-difference model in the sample of high-skilled workers in and out of the labor force, using school enrollment as the dependent variable. We find that young individuals are 5.2 percentage points (panel E of Table 6) more likely to be enrolled in university after the reform than older individuals. This pattern is consistent with lower dropout rates, delaying the labor market entry for a certain fraction of the increase 
in enrollment documented in Table 3. Moreover, the magnitude of the coefficient explains almost entirely the reduction in labor force participation found earlier.

If the reform changes incentives to obtain higher education, this can cause another type of sample selection. Similar to the previous case, our estimates are upward biased if individuals are less likely to obtain higher education after the implementation of the reform and downward biased in the opposite case since that would increase the labor supply. ${ }^{24}$ To test for changes in the decision to pursue university coursework, we estimate a specification based on equation (1) in the sample of high school and university trained labor market participants, using $U_{i}$ (the indicator for whether the individual has university training) as dependent variable. The estimated effect listed in panel F of Table 6, although positive (4 percentage points), is small and only marginally significant. ${ }^{25}$ This is also consistent with the fact that the capacity constraints in higher education did not change in the short term.

Our estimates are upward biased if the education reform encourages high-skilled workers to accept (temporary) jobs that require less education. This is unlikely to be the case, however, as Serneels (2007) finds in the Ethiopian context that high-skilled unemployed individuals do not generally take on temporary employment after leaving university because social networks are usually more effective when the applicant is unemployed and because employment of poor quality can damage the reputation of the individual and thus reduce the probability of obtaining a more desirable job in the future. We return to this issue in more detail in the next section.

Finally, we have two pieces of suggestive evidence in support of our last assumption, that the composition of the treated group and of the control group was not affected by the

\footnotetext{
${ }^{24}$ One exception to this is if the reform changes the ability distribution of the university-educated workforce (if, for instance, returns to education increase). In this case, the number of employed individuals could go up even if labor supply increases as the gap between labor quality demanded and offered shrinks. However, this is an effect of the reform we would probably want to include in our estimation.

${ }^{25}$ These results can also be interpreted as suggestive evidence against the skill-biased growth scenario. In particular, an economic expansion that leads to increased demand of high-skilled young workers would create incentives for these individuals to enter the labor market as soon as possible. In other words, individuals would have an incentive to drop out of school as soon as their level of education would allow them sufficiently high earnings. However, our results indicate exactly the opposite pattern (an increase in enrollment) and suggest that people tend to stay longer in school.
} 
reform. First, in Table 5 we find similar effects when we include our full set of controls for all alternative definitions of treatment. This suggests that the observable characteristics did not vary between treatment and control, before and after the reform, in a way correlated with the reform. Second, we showed in Table 6 that the reform did not significantly impact the decision to pursue higher education. This again lends support to the assumption that the structure of the treated and control groups was mainly unchanged after the reform.

Taken together, the tests conducted in this section suggest that our estimates capture the effect of the PDEF reform on the employment rate of young high-skilled workers. In addition, the lack of evidence of an increase in the employment of older high-skilled individuals or of high school-educated individuals supports our initial hypothesis that the effect of the reform was to reduce the gap between the quality of labor demanded and supplied in the high-skill labor market.

\subsection{Possible sources of employment growth}

In this section, we investigate some potential sources for the additional employment among young high-skilled workers. Unfortunately, our data does not include information on occupation or on the employer side, which would allow us to directly test if job quality improved after the reform. Instead, we use the industry of employment and the employer type as proxies for changes in the labor market prospects of university-trained workers.

We start by estimating a multinomial probit specification similar to equation (1) for the choice of industry on the sample of working high-skilled individuals. We combine the different industries into three groups: manufacturing, services, and other industries. ${ }^{26}$ Panel A of Table 7 shows the marginal effects of the reform effect, which are the difference between younger workers and older workers in the probability of choosing the corresponding industry as compared to the other two groups after the reform (hence, the three marginal effects sum

\footnotetext{
26"Manufacturing" groups mining, manufacturing and other public utilities. "Services" includes trade, tourism, transportation and communication, finance, insurance, and real estate, and personal services. "Other industries" combines the other industries of employment, including agriculture.
} 
up to one). The coefficients indicate that younger workers are significantly more likely to work in the services industry (12 percentage points) and less likely to work in manufacturing (7.8 percentage points) or another type of industry (4.2 percentage points). In a study of the Senegalese economy in 2003, Echevin and Murtin (2009) find that the returns to education are among the highest in the trade and services sectors. Therefore, our results suggest that young high-skilled workers are able to find jobs that better reward their education level after the reform. In addition, the fact that these jobs are not in manufacturing or agriculture, the main determinants of the strong macroeconomic growth during the study period, suggests again that our findings are not driven by the expansion of the economy.

Panel B of the same Table reports the estimates from a multinomial probit similar to the one above where the dependent variable indicates the type of employer of the individual: selfemployment, government, or a public or private company. The results indicate that young high-skilled workers are much less likely to be self-employed (by 11.9 percentage points) and more likely to be employed by the government (by 13.3 percentage points), while the probability of working for a public or private enterprise is more or less stable (1.4 percentage points). Since self-employment is generally perceived as a last-resort activity and public employment usually provides the highest returns to education (Teal, 2011), these estimates again suggest that young high-skilled workers are better able to find higher-quality jobs. ${ }^{27}$

\section{Conclusions and policy recommendations}

In this paper, we analyzed the short-term effects of an education reform targeting higher education on the labor market outcomes of high-skilled workers. Since in the very short term the reform changes only the quality of, but not access to, higher education, we estimate the effect of an improved quality of education on the employment prospects of university-trained

\footnotetext{
${ }^{27}$ One caveat to this interpretation is if the reduction in self-employment is due to tighter credit constraints. In this case, individuals could choose lower paying jobs. However, this situation cannot explain why they find jobs with the government or our previous results that individuals tend to work more in service industries, which tend to reward education better.
} 
individuals. We find that the reform led to significant increases in the employment rate for various definitions of exposure to the reform and that these estimates are robust to a host of specification checks. We also find that young workers are better able to find jobs in the services sector and in government, all of which are presumably associated with better returns to education.

Our results contribute to the existing literature on education in the developing world. In particular, to our knowledge, this is the first study of the effects of quality at the higher education level on labor market outcomes in developing countries. Our findings indicate that quality improvements in higher education could have significant positive effects not only on the labor market outcomes of university-trained individuals, but also on the dropout rate and on university attendance. ${ }^{28}$ In addition, as individuals are able to find jobs that better exploit their training, this also creates the potential for long-term economic growth. Finally, our results provide evidence in support of the hypothesis that developing countries such as Senegal experience significant differences between the quality demanded and offered in the high-skilled labor market. The immediate impact of a reform improving the quality of higher education is most likely to fulfill the backlogged demand for better trained workers, leading to a relatively sharp increase in the employment rate of young workers. It is likely that the longer-term effect of the reform will be lower, even as employers adjust to the expected influx of better quality workers.

There are several limitations to our study. First, as mentioned above, we can only examine the very short-term effects of the reform. However, in volatile political environments such as in much of the developing world, having proof of immediate results encourages the continued application of the reform and the implementation in other countries. Second, we do not have information on wages or job quality so we cannot determine whether the increase in

\footnotetext{
${ }^{28}$ These results are also in line with the recommendations made in the context of the Program for Quality Improvement, Equity, and Transparency (Programme d'Amélioration de la Qualité, de l'Equité et de la Transparence, PAQUET) 2013-2025, phase III of the PDEF, in terms of quality of education and of strengthening the ties with the labor market (Ministère de l'enseignement supérieur et de la recherche, 2013; Gouvernement du Sénégal, 2013).
} 
employment is associated with better jobs. We do not consider this a major concern, as we do not find any evidence in our robustness tests of factors pushing younger high-skilled workers to accept lower quality jobs after the reform. On the contrary, we find evidence that young individuals tend to work more in services industries, which were previously found to offer one of the highest return to education (Echevin and Murtin, 2009). Third, we cannot distinguish between full or partial exposure to the reform, which means that we are likely estimating lower bounds for the short-term effects of the reform. Fourth, we are unable to identify the exact channel through which the reform leads to improved labor market prospects (e.g., retention of better students, better quality instructors, better alignment of educational programs with labor market demands, etc.). Finally, we have relatively small samples, mostly due to the shortage of high-skilled workers in the developed world. While this is likely to lower the precision of our estimates, the estimated effects are robust to a host of specification checks and generally statistically significant.

The Senegal experience provides an important policy lesson to other sub-Saharan African countries, particularly those experiencing large unemployment rates among young university graduates. Our main results suggest that policies improving the quality of education at the university level can lead to significant positive effects. Therefore, there should be a concerted effort to improve the quality of education at all levels. By aiming to align the skill requirements of employers to the training of university graduates, governments can potentially improve the labor market outcomes of these high-skilled individuals on several dimensions: better employment prospects, jobs of better quality, and potentially higher wages and more job security. Since none of these changes would come at the expense of other workers, the end result should be higher overall economic growth. Indeed, the Program for the Improvement of Quality, Equity and Transparency in the Education and Training Sector (Programme d'Amélioration de la Qualité, de l'Équité et de la Transparence du secteur de l'Éducation et de la Formation, PAQUET-EF), the successor of the PDEF in 2012, saw as an opportunity the fact that the labor market places more and more emphasis on the education 
and training of new graduates because of an increasing need of a high-skilled labor force. This will necessarily involve improvements in the quality of education in Senegal. 


\section{References}

Agence Nationale de la Statistique et de la Démographie (2004), "L'emploi, le chomage et les conditions d'activité dans l'agglomeration de Dakar," .

Archivage National des Données du Sénégal (2012a), "Enquête sénégalaise auprès des ménages 2ème édition," Available online at http://anads.ansd.sn/index.php/catalog/ 10\#page=sampling\&tab=study - desc .

—_ (2012b), "Sénégal — Enquête de suivi de la pauvreté au Sénégal 2005," Available online at http://anads.ansd.sn/index.php/catalog/13\#page=sampling\&tab= study-desc.

Bacolod, Marigee P., and Justin L. Tobias (2006), "Schools, school quality and achievement growth: Evidence from the Philippines," Economics of Education Review 25(6), 619-632.

Barro, Robert J., and Jong-Wha Lee (1994), "Sources of economic growth," CarnegieRochester Conference Series on Public Policy 40, 1-46.

(2013), "A new data set of educational attainment in the world, 1950-2010," Journal of Development Economics 104, 184-198.

Bedi, Arjun Singh, and John H. Y. Edwards (2002), "The impact of school quality on earnings and educational returns - evidence from a low-income country," Journal of Development Economics 68, 157-185.

Behrman, Jere R., and Nancy Birdsall (1983), "The quality of schooling: Quantity alone is misleading," American Economic Review 73(5), 928-946.

Behrman, Jere R., David Ross, and Richard Sabot (2008), "Improving quality versus increasing the quantity of schooling: Estimates of rates of return from rural Pakistan," Journal of Development Economics 85(1-2), 94-104. 
Bloom, David E., David Canning, Kevin Chan, and Dara Lee Luca (2006), "Higher education and economic growth in Africa," World Bank Working Paper, Africa Region, Human Development Sector.

Böckerman, Petri, Ulla Hämäläinen, and Roope Uusitalo (2009), "Labour market effects of the polytechnic education reform: The Finnish experience," Economics of Education Review 28(6), 672-681.

Calvès, Anne-Emmanuèle, and Bruno Schoumaker (2004), "Deteriorating economic context and changing patterns of youth employment in urban Burkina Faso: 1980-2000," World Development 32(8), 1341-1354.

Castelló, Amparo, and Rafael Doménech (2002), "Human capital inequality and economic growth: Some new evidence," Economic Journal 112(478), C187-C200.

Diagne, Abdoulaye (2012), "Evaluation du Programme decennal de l'education et de la formation 2000-2011," Ministère de l'éducation, Direction de la plannification de la reforme et de l'éducation.

Direction de la planification et de la réforme de l'éducation (2008), "Rapport national sur la situation de l'éducation 2007," .

— (2009), "Rapport national sur la situation de l'éducation 2008," .

Duflo, Esther (2001), "Schooling and labor market consequences of school construction in Indonesia: Evidence from an unusual policy experiment," American Economic Review 91(4), 795-813.

(2004), "The medium run effects of educational expansion: Evidence from a large school construction program in Indonesia," Journal of Development Economics 74, 163197. 
Echevin, Damien, and Fabrice Murtin (2009), "What determines productivity in Senegal? Sectoral disparities and the dual labour market," Journal of Development Studies 45(10), $1707-1730$.

Fan, C. Simon, and Oded Stark (2007), "International migration and 'educated unemployment'," Journal of Development Economics 83, 76-87.

Glewwe, Paul (1999), The economics of school quality investments in developing countries: An empirical study of Ghana, St. Martin's Press, in association with Centre for the Study of African Economies, University of Oxford.

Gouvernement du Sénégal (2013), "Programme d'amélioration de la qualité, de l'équité et de la transparence (PAQUET) - Secteur éducation formation 2013-2025," .

Guarcello, Lorenzo, Marco Manacorda, Furio Rosati, Jean Farès, Scott Lyon, and Cristina Valdivia (2008), "School to work transitions: Regional overview," in Marito Garcia and Jean Farès, eds., Youth in Africa's Labor Market, chap. 7, 107-148, World Bank Publications.

Handa, Sudhanshu, and Kenneth R. Simler (2006), "Quality or quantity? The supply-side determinants of primary schooling in a poor rural economy," Journal of African Economies 15(1), 59-90.

Hanushek, Eric A. (2009), "School policy: Implications of recent research for human capital investments in South Asia and other developing countries," Education Economics 17(3), 291-313.

(2013), "Economic growth in developing countries: The role of human capital," Economics of Education Review 37, 204-212.

Hanushek, Eric A., Victor Lavy, and Kohtaro Hitomi (2008), "Do students care about school 
quality? Determinants of dropout behavior in developing countries," Journal of Human Capital 2(1), 69-105.

Hanushek, Eric A., and Ludger Woessmann (2008), "The role of cognitive skills in economic development," Journal of Economic Literature 46(3), 607-668.

Hanushek, Eric A., Ludger Woessmann, and Lei Zhang (2011), "General education, vocational education, and labor-market outcomes over the life-cycle," NBER Working Paper no. 17504 .

Harbison, Ralph W., and Eric A. Hanushek (1992), Educational performance of the poor: Lessons from rural northeast Brazil, Oxford University Press.

Hotz, V. Joseph, Susan Williams McElroy, and Seth G. Sanders (2005), "Teenage childbearing and its life cycle consequences: Exploiting a natural experiment," Journal of Human Resources 40(3), 683-715.

Hotz, V. Joseph, Charles H. Mullin, and Seth G. Sanders (1997), "Bounding causal effects using data from a contaminated natural experiment: Analysing the effects of teenage chilbearing," Review of Economic Studies 64(4), 575-603.

Kaarsen, Nicolai (2014), "Cross-country differences in the quality of schooling," Journal of Development Economics 107, 215-224.

Kimenyi, Mwangi S. (2011), "Contribution of higher education to economic development: A survey of international evidence," Journal of African Economies 20(suppl 3), iii14-iii49.

Malamud, Ofer, and Cristian Pop-Eleches (2010), "General education versus vocational training: Evidence from an economy in transition," Review of Economics and Statistics 92(1), $43-60$.

Manuelli, Rodolfo E., and Ananth Seshadri (2014), "Human capital and the wealth of nations," American Economic Review 104(9), 2736-2762. 
Mingat, Alain (1998), "The strategy used by high-performing Asian economies in education: Some lessons for developing countries," World Development 26(4), 695-715.

Ministère de l'enseignement supérieur et de la recherche (2013), "Concertation nationale sur l'avenir de l'enseignement supérieur au Sénégal," .

Ministère de l'économie et des finances du Sénégal (2001), "Confection du budget par objectifs pour 2001-2003 des Ministéres de l'éducation nationale et de l'enseignement supérieur," .

Ministère de l'éducation (2003), "Programme de développement de l'éducation et de la formation (éducation pour tous)," .

Moll, Peter G. (1992), "Quality of education and the rise in returns to schooling in south africa, 1975-1985," Economics of Education Review 11(1), 1-10.

Ordine, Patrizia, and Giuseppe Rose (2011), "Inefficient self-selection into education and wage inequality," Economics of Education Review 30(4), 582-597.

Pauw, Kalie, Morné Oosthuizen, and Carlene van der Westhuizen (2008), "Graduate unemployment in the face of skills shortages: A labour market paradox," South African Journal of Economics 76(1), 45-57.

Pritchett, Lant (2001), "Where has all the education gone?" World Bank Economic Review 15(3), 367-391.

Puhani, Patrick A. (2012), "The treatment effect, the cross difference, and the interaction term in nonlinear 'difference-in-differences' models," Economics Letters 115(1), 85-87.

Saavedra, Juan Esteban (2009), "The learning and early labor market effects of college quality: A regression discontinuity analysis," Working paper.

Samb, Moussa M., Babacar Thiaw, and Mamadou Diong (1999), "Projet de recherche sur le suivi des diplômes des universités africaines dans le milieu du travail: Cas de l'Université Cheikh Anta Diop de Dakar," Association of African Universities Research Paper No. 7. 
Schoellman, Todd (2012), "Education quality and development accounting," Review of Economic Studies 79(1), 388-417.

Serneels, Pieter (2007), "The nature of unemployment among young men in urban Ethiopia," Review of Development Economics 11(1), 170-186.

Teal, Francis (2011), "Higher education and economic development in Africa: A review of channels and interactions," Journal of African Economies 20(suppl 3), iii50-iii79.

Zhang, Liang (2005), Does Quality Pay? Benefits of Attending a High-Cost, Prestigious College, New York: Routledge.

Zhong, Hai (2011), "Returns to higher education in China: What is the role of college quality?" China Economic Review 22(2), 260-275. 


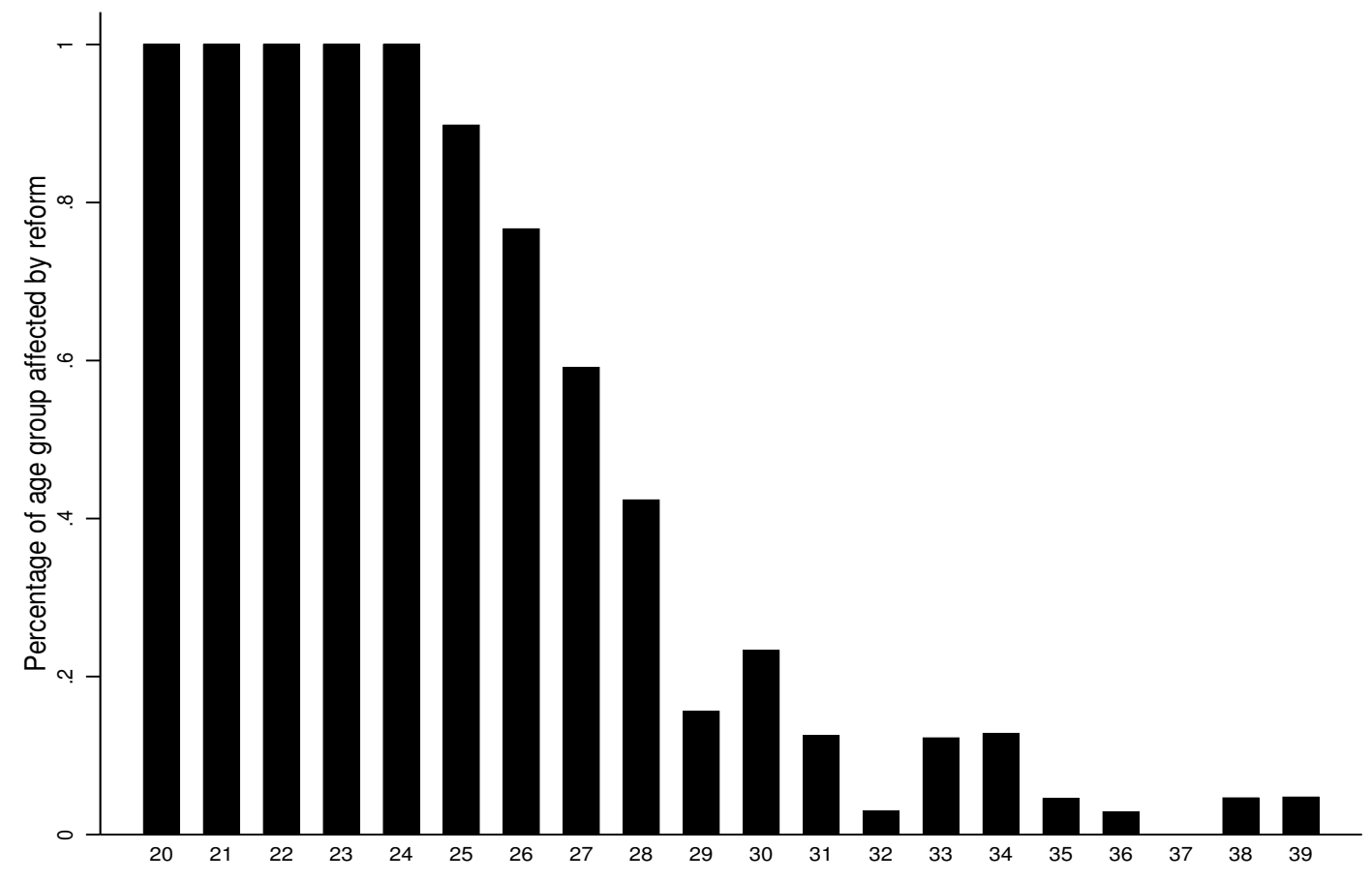

(a) Proportion of university graduates affected by PDEF, by age

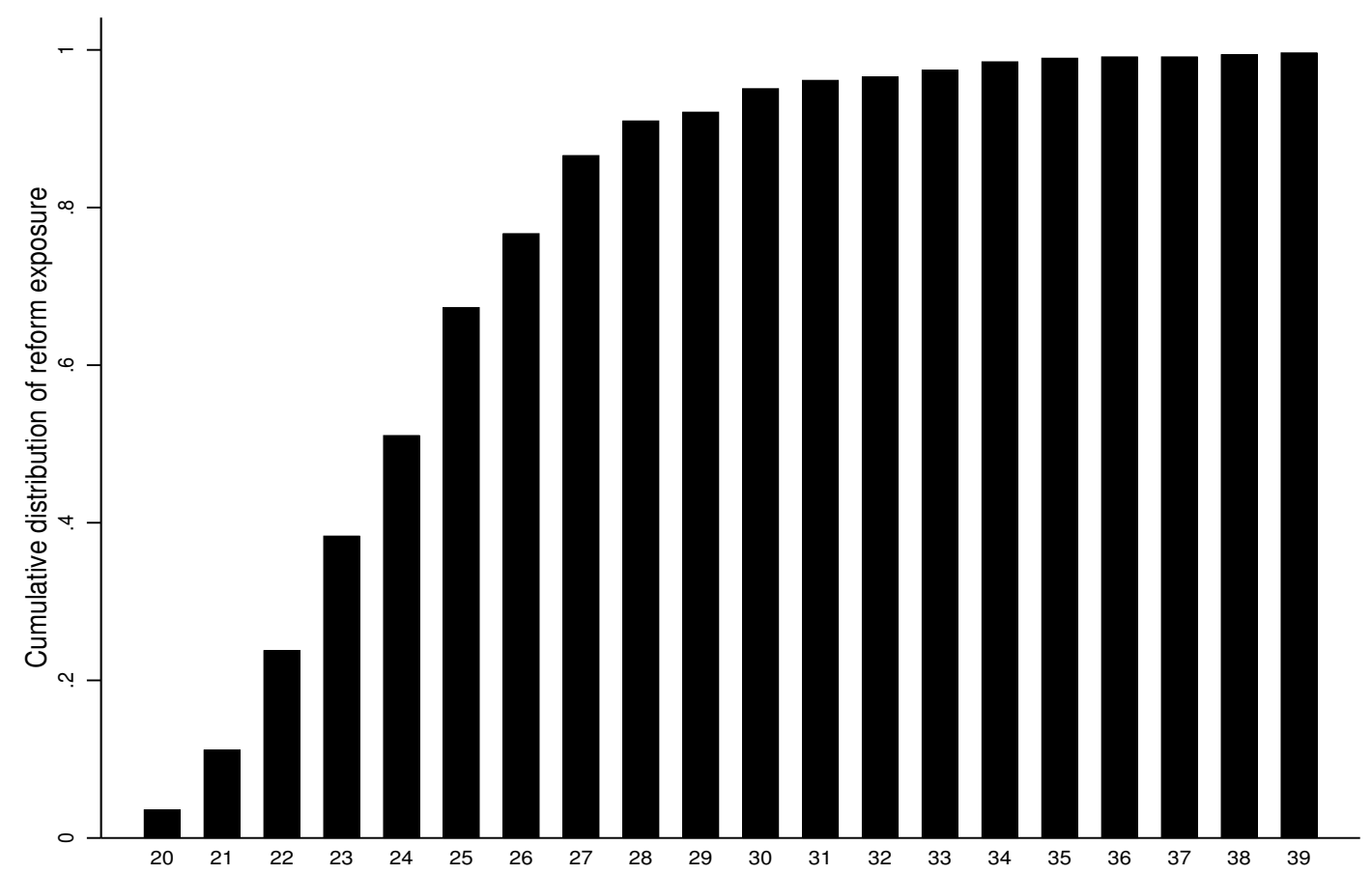

(b) Cumulative distribution of PDEF exposure, by age

Figure 1: An estimate of contamination in the treated and in the control group 
Table 1: Unemployment rate in Dakar, by education (2002)

\begin{tabular}{lcccc}
\hline & No education & Primary & High school & University \\
\hline Head of household & 0.061 & 0.068 & 0.071 & 0.027 \\
Dependent & 0.097 & 0.133 & 0.179 & 0.238 \\
\hline
\end{tabular}

Source: Agence Nationale de la Statistique et de la Démographie (2004). 
Table 2: Education expenditures

\begin{tabular}{|c|c|c|c|c|c|c|}
\hline & 2000 & 2001 & 2002 & 2003 & 2004 & 2005 \\
\hline \multicolumn{7}{|c|}{ A. Higher education expenses (\% of education spending) } \\
\hline Projected & 20.2 & 19.7 & 19.3 & 19.2 & 24.4 & 23.4 \\
\hline Actual & 25.6 & 26.1 & 26.5 & 23.8 & 26.5 & 23.8 \\
\hline \multicolumn{7}{|c|}{ B. Public spending on education } \\
\hline Percent of GDP & 3.16 & 3.29 & 3.39 & 3.51 & 3.86 & 5.15 \\
\hline
\end{tabular}

Source: Direction de la planification et de la réforme de l'éducation (2008), World Development Indicators. 


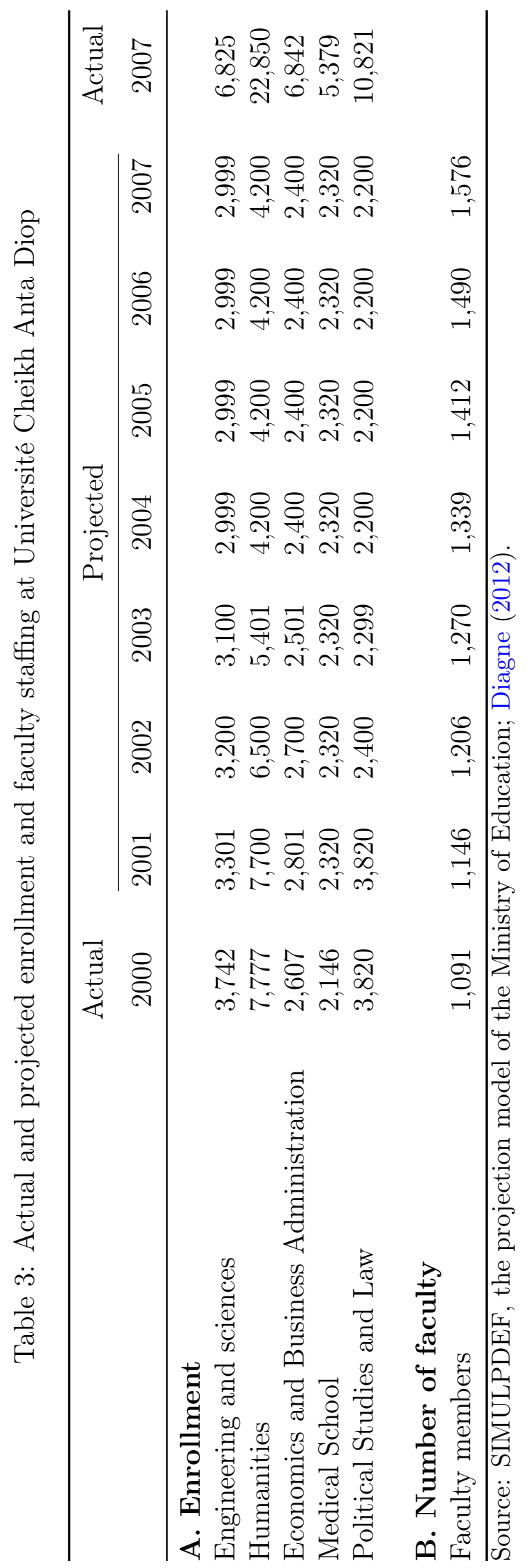


Table 4: Sample characteristics, treatment defined as 20-26 year-old

\begin{tabular}{|c|c|c|c|c|}
\hline & \multicolumn{2}{|c|}{ Pre-intervention (ESAM-II) } & \multicolumn{2}{|c|}{ Post-intervention (ESPS) } \\
\hline & $\begin{array}{c}\text { Treated } \\
20-26 \text { year old } \\
\text { (1) }\end{array}$ & $\begin{array}{c}\text { Control } \\
27-39 \text { year old } \\
\text { (2) }\end{array}$ & $\begin{array}{c}\text { Treated } \\
20-26 \text { year old } \\
\text { (3) }\end{array}$ & $\begin{array}{c}\text { Control } \\
\text { 27-39 year old } \\
\text { (4) }\end{array}$ \\
\hline Employment rate & 0.575 & 0.925 & 0.737 & 0.898 \\
\hline Age & $\begin{array}{l}23.988 \\
(0.415)\end{array}$ & $\begin{array}{l}32.868 \\
(0.358)\end{array}$ & $\begin{array}{l}24.008 \\
(0.333)\end{array}$ & $\begin{array}{l}32.635 \\
(0.263)\end{array}$ \\
\hline Male & 0.742 & 0.840 & 0.812 & 0.639 \\
\hline Married & 0.092 & 0.449 & 0.228 & 0.572 \\
\hline \multicolumn{5}{|c|}{ Relationship to household head } \\
\hline Household head & 0.000 & 0.260 & 0.063 & 0.283 \\
\hline Spouse & 0.000 & 0.016 & 0.000 & 0.071 \\
\hline Child & 0.608 & 0.357 & 0.707 & 0.465 \\
\hline Other & 0.392 & 0.367 & 0.230 & 0.182 \\
\hline \multicolumn{5}{|l|}{ Industry } \\
\hline Manufacturing & 0.071 & 0.040 & 0.050 & 0.072 \\
\hline Services & 0.143 & 0.218 & 0.374 & 0.247 \\
\hline Other & 0.361 & 0.667 & 0.312 & 0.578 \\
\hline \multicolumn{5}{|l|}{ Employer } \\
\hline Self-employed & 0.264 & 0.249 & 0.134 & 0.167 \\
\hline Government & 0.193 & 0.414 & 0.253 & 0.405 \\
\hline Company & 0.118 & 0.262 & 0.350 & 0.326 \\
\hline \multicolumn{5}{|l|}{ Urbanization } \\
\hline Urban Dakar & 0.600 & 0.654 & 0.712 & 0.660 \\
\hline Other cities & 0.118 & 0.202 & 0.141 & 0.245 \\
\hline Rural & 0.281 & 0.145 & 0.147 & 0.096 \\
\hline Observations & 19 & 115 & 61 & 443 \\
\hline
\end{tabular}

Note: All statistics are weighted using sample weights. Married includes polygamous and monogamous marriages. 
Table 5: Baseline results

\begin{tabular}{|c|c|c|c|c|}
\hline & \multicolumn{2}{|c|}{$\begin{array}{l}\text { Difference-in-difference } \\
\qquad(\mathrm{N}=638)\end{array}$} & \multicolumn{2}{|c|}{$\begin{array}{l}\text { Triple-difference } \\
\quad(\mathrm{N}=4183)\end{array}$} \\
\hline & $\begin{array}{l}\text { No controls } \\
\text { (1) }\end{array}$ & $\begin{array}{l}\text { With controls } \\
\text { (2) }\end{array}$ & $\begin{array}{l}\text { No controls } \\
(3)\end{array}$ & $\begin{array}{l}\text { With controls } \\
\text { (4) }\end{array}$ \\
\hline \multicolumn{5}{|c|}{ A. Preferred definition of exposure to PDEF (20-26 year old) } \\
\hline Effect of PDEF & $\begin{array}{c}0.120^{* *} \\
(0.049) \\
{[-0.025,0.269]}\end{array}$ & $\begin{array}{c}0.090^{* *} \\
(0.044) \\
{[-0.110,0.253]}\end{array}$ & $\begin{array}{c}0.130 \\
(0.079) \\
{[-0.113,0.384]}\end{array}$ & $\begin{array}{c}0.110 \\
(0.073) \\
{[-0.144,0.398]}\end{array}$ \\
\hline \multicolumn{5}{|c|}{ B. Alternative definitions of exposure to PDEF } \\
\hline 20-25 years old & $\begin{array}{l}0.234^{* * *} \\
(0.068)\end{array}$ & $\begin{array}{l}0.248^{* * *} \\
(0.057)\end{array}$ & $\begin{array}{l}0.317^{* * *} \\
(0.102)\end{array}$ & $\begin{array}{l}0.314^{* * *} \\
(0.084)\end{array}$ \\
\hline 20-27 years old & $\begin{array}{r}0.081^{*} \\
(0.047)\end{array}$ & $\begin{array}{c}0.056 \\
(0.048)\end{array}$ & $\begin{array}{c}0.115 \\
(0.079)\end{array}$ & $\begin{array}{c}0.115 \\
(0.078)\end{array}$ \\
\hline 20-28 years old & $\begin{array}{c}0.048 \\
(0.045)\end{array}$ & $\begin{array}{c}0.035 \\
(0.040)\end{array}$ & $\begin{array}{c}0.055 \\
(0.076)\end{array}$ & $\begin{array}{c}0.067 \\
(0.073)\end{array}$ \\
\hline 20-29 years old & $\begin{array}{c}0.034 \\
(0.039)\end{array}$ & $\begin{array}{c}0.017 \\
(0.032)\end{array}$ & $\begin{array}{c}0.035 \\
(0.065)\end{array}$ & $\begin{array}{c}0.037 \\
(0.063)\end{array}$ \\
\hline
\end{tabular}

Notes: Each cell represents marginal effects from a separate probit regression. All specifications use sample weights and include dummy variables for the post-intervention period and for the control group. In addition, columns 2 and 4 include a second polynomial in age and dummies for sex, residence (rural, urban other than Dakar; reference category: urban Dakar), region (10 regions; reference category: Dakar), married (mono- or polygamous; reference category: single) and relationship to household head (spouse, child, or other; reference category: head of household). Robust standard errors clustered at the region level in parentheses, bootstrapped biased-corrected 95 percent confidence interval (1,000 replications) in brackets. ${ }^{*} \mathrm{p}<.1,{ }^{*} \mathrm{p}<.05,{ }^{* * *} \mathrm{p}<.01$. 


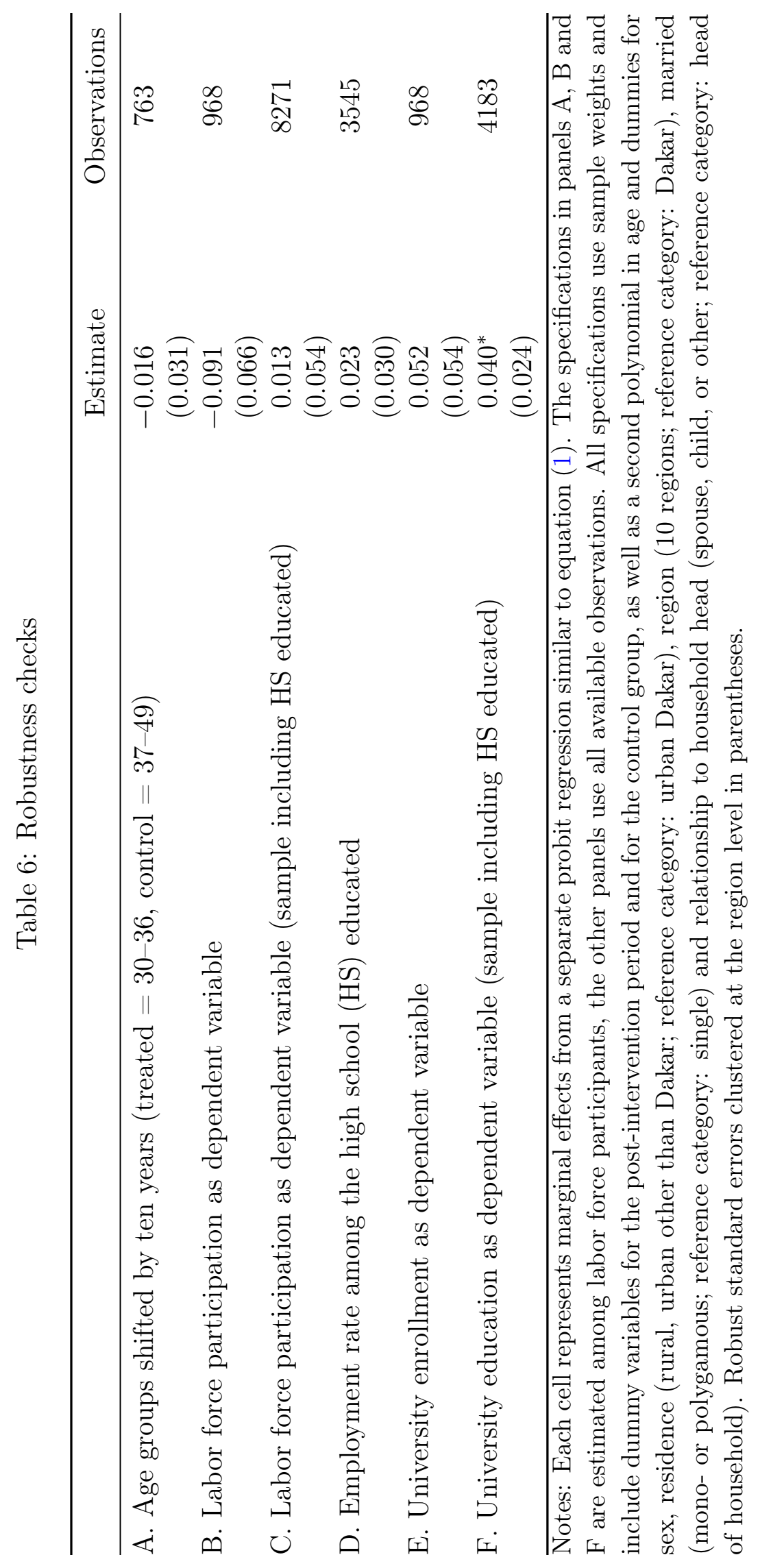


Table 7: Possible sources of employment growth

Estimate

A. Industry $(\mathrm{N}=379)$

Manufacturing

$-0.078^{* * *}$

$(0.023)$

Services

$0.120^{* * *}$

$(0.026)$

Other

$(0.030)$

B. Employer $(\mathrm{N}=379)$

Self employment

$-0.119^{*}$

$(0.064)$

Government

0.133

$(0.101)$

$-0.014$

Private and public enterprises

$(0.076)$

Notes: Each panel represents a different multinomial probit regression with dependent variable indicated in the panel title. Each cell represents the marginal effect of the reform calculated for the corresponding outcome. All specifications use sample weights and include dummy variables for the post-intervention period and the control group. Robust standard errors clustered at the region level in brackets. ${ }^{*} \mathrm{p}<.1,{ }^{* *} \mathrm{p}<.05,{ }^{* * *} \mathrm{p}<.01$. 